\title{
Advanced implantation in mink (Mustela vison) treated with medroxyprogesterone acetate during early embryonic diapause
}

\author{
P. Concannon, T. Pilbeam* and H. Travis $\dagger$ \\ Department of Physical Biology, New York State College of Veterinary Medicine, \\ *Department of Animal Science, New York State College of Agriculture and Life Sciences, and \\ †U.S.D.A. Sheep and Fur Animal Experiment Station, Cornell University, Ithaca, \\ New York 14853, U.S.A.
}

\begin{abstract}
Summary. Adult and pubertal female mink mated on 4 March were administered 2.5 mg medroxyprogesterone acetate (MPA) or control vehicle on 9-11 March. Pregnancies were shorter $(P<0.01)$ in adult $(60 \pm 2$ days $)$ than in pubertal $(72 \pm$ 0.7 days) control animals. Treatment with MPA reduced $(P<0.01)$ the length of pregnancy in both adult $(51 \pm 1$ days $)$ and pubertal $(60 \pm 2$ days $)$ mink but did not significantly affect serum progesterone levels on 3-4 April. Observations at laparotomy during April confirmed the effects of age and treatment on the time of implantation and suggested that implantation sites become grossly visible 28 days before parturition. It is concluded that administration of a progestagen during early embryonic diapause can advance the time of implantation in mink.
\end{abstract}

\section{Introduction}

Various aspects of the annual reproductive cycle and pregnancy in mink (Mustela vison) have been reviewed in detail (Hansson, 1947; Enders, 1952; Asdell, 1964; Venge, 1973-1974; Pilbeam, Concannon \& Travis, 1979). In brief, mink are seasonally breeding, induced ovulators in which, following matings in late February or early March, there is a variable period of embryonic diapause before implantation in early April. Parturition in late April or early May occurs approximately 28-30 days after implantation. Mink mated around 1 March have a period of delayed implantation of 30-40 days and such animals are therefore suitable for studying the endocrine events controlling the process of implantation.

Oestradiol levels are maximal just before the breeding season, fall during the 3- to 4-week period of oestrus and early diapause, and remain low during pregnancy (Pilbeam et al., 1979). Corpora lutea do not appear functional on a gross or histological basis until late March (Enders, 1952). Circulating progesterone levels remain low during oestrus, increase at or shortly after the vernal equinox, reach near peak levels about the time of implantation, and fall to low levels around the time of parturition (Møller, 1973; Murphy \& Moger, 1977; Allais \& Martinet, 1978; Pilbeam et al., 1979). The initial increase in progesterone normally occurs at or after the vernal equinox regardless of the time of mating and ovulation but it can be advanced slightly by alterations in the photoperiod (Allais \& Martinet, 1978). The induction of early implantation by alterations in the photoperiod has also been reported (Hansson, 1947; Holcomb, Schaible \& Ringer, 1962; Aulerich, Holcomb, Ringer \& Schaible, 1963).

We have previously suggested that termination of embyronic diapause and the initiation of implantation occur in response to the changes in circulating levels of progesterone associated with the activation of ovarian progesterone secretion that occurs following the vernal equinox 
(Pilbeam et al., 1979). However, there is no direct evidence that progesterone can induce implantation in mink. All treatments with progesterone, progesterone in combination with oestrogen, or a synthetic progestagen during delayed implantation have failed to advance the time of implantation or shorten the length of pregnancy (Hansson, 1947; Hammond, 1951; Franklin, 1958; Cochrane \& Shackelford, 1962; Holcomb, 1967). This may have been because the hormone levels produced by the treatments did not mimic closely enough those occurring during pregnancy. Medroxyprogesterone acetate (MPA) is a long-acting progestagen, injection of which produces sustained elevations in the circulation for several weeks (Kirton \& Cornette, 1974; Hansel, Concannon \& McEntee, 1977). We therefore studied the effect of MPA on mink in delayed implantation.

\section{Materials and Methods}

\section{Animals and treatments}

Brown-eyed, pastel mink were raised and maintained in outdoor pens using standard farming procedures at the U.S.D.A. Sheep and Fur Animal Experiment Station at Cornell University, Ithaca, New York $\left(42^{\circ} \mathrm{N}\right)$, as previously described (Travis \& Schaible, 1959). They were fed a standard ration.

Groups of 5 adult females and groups of 5 pubertal (kit) females received injections of MPA or of control vehicle on 9 and 11 March after matings on 4 March. Each of the 4 groups contained 4 animals that remated on 5 March and 1 that did not remate. The adults were 22 or 34 months old and weighed $1.02 \pm 0.03$ (s.e.m.) kg. The kits were 10 months old and weighed $0.90 \pm 0.04 \mathrm{~kg}$. The MPA (Depo-Provera: Upjohn Company, Kalamazoo, U.S.A.) was injected intramuscularly in doses of $2.0 \mathrm{mg} / \mathrm{kg}$ on $9 \mathrm{March}$ and $0.5 \mathrm{mg} / \mathrm{kg}$ on 11 March. Appropriate volumes of the vehicle for MPA (Vehicle No. 112: Upjohn Company) were administered to control mink on the same dates. Day 0 of pregnancy was considered to be 4 March for mink that whelped. The mink were checked at 10:00 and 16:00 h daily from 20 April to 20 May and the day on which a litter was found was considered the day of parturition.

\section{Laparotomies}

During the month of April, 15 of these mink, and 3 extra mink that mated on 4 and 5 March but received no injections, were laparotomized to determine any differences in the presence or size of implantations related to age or treatment (see Text-fig. 1). Anaesthesia for the laparotomies was induced by pentobarbitone sodium (Nembutal: Abbot) given intraperitoneally $(30 \mathrm{mg} / \mathrm{kg}$ ). Uterine diameters were measured to the nearest $0.25 \mathrm{~mm}$ at 2 or 3 implantation sites and at 2 or 3 areas between the sites. Implantation size was calculated as the difference between the mean uterine diameters at implantation sites and at the intersite areas. When implanted embryos were not observed in mink that subsequently whelped the implantation size at the time of laparotomy was considered as $0.0 \mathrm{~mm}$.

\section{Blood collection and hormone assays}

Blood samples were collected by jugular venepuncture from 5 control mink ( 3 adults, 2 kits) and 5 treated mink ( 3 adults, 2 kits) when laparotomized on 3-4 April, and from 2 control kits and 2 treated adults on 28 April. Samples were allowed to clot for $18-24 \mathrm{~h}$ at $5^{\circ} \mathrm{C}$ and centrifuged at $800 \mathrm{~g}$. Serum was stored at $-20^{\circ} \mathrm{C}$ until assayed. Levels of progesterone and MPA in each sample were determined by radioimmunoassay as previously described. The antiserum to progesterone was specific (Devilla, Roberts, Wiest, Mikhail \& Flickinger, 1972) and the antiserum to MPA does not cross-react with endogenous steroids (Cornette, Kirton \& Duncan, 
1971). Recoveries of progesterone or MPA (2, 10 and $20 \mathrm{ng} / \mathrm{ml}$ ) added to serum of ovariectomized mink were $96-103 \%$. The progesterone and MPA assays in the present study had sensitivities of 0.6 and $0.8 \mathrm{ng} / \mathrm{ml}$, and intra-assay coefficients of 6 and $9 \%$, respectively. Both assays routinely have inter-assay coefficients of variation of $<14 \%$ based on $2-4$ serum samples $(2-50 \mathrm{ng} / \mathrm{ml})$ run in each assay.

\section{Statistical analysis}

All means are reported as \pm s.e.m. The lengths of pregnancy and the litter sizes were subjected to a computerized analysis of variance (Henderson, 1959). Statistical differences between means were determined by LSD tests or Student's $t$ tests (Steel \& Torrie, 1960).

\section{Results}

As shown in Text-fig. 1, implantations in mink treated with MPA were observed earlier and were larger than those in control mink of the same age. When implantation size was related to the time of parturition (Text-fig. 2) it was clear that implantation sites became grossly visible about 28 days before parturition.

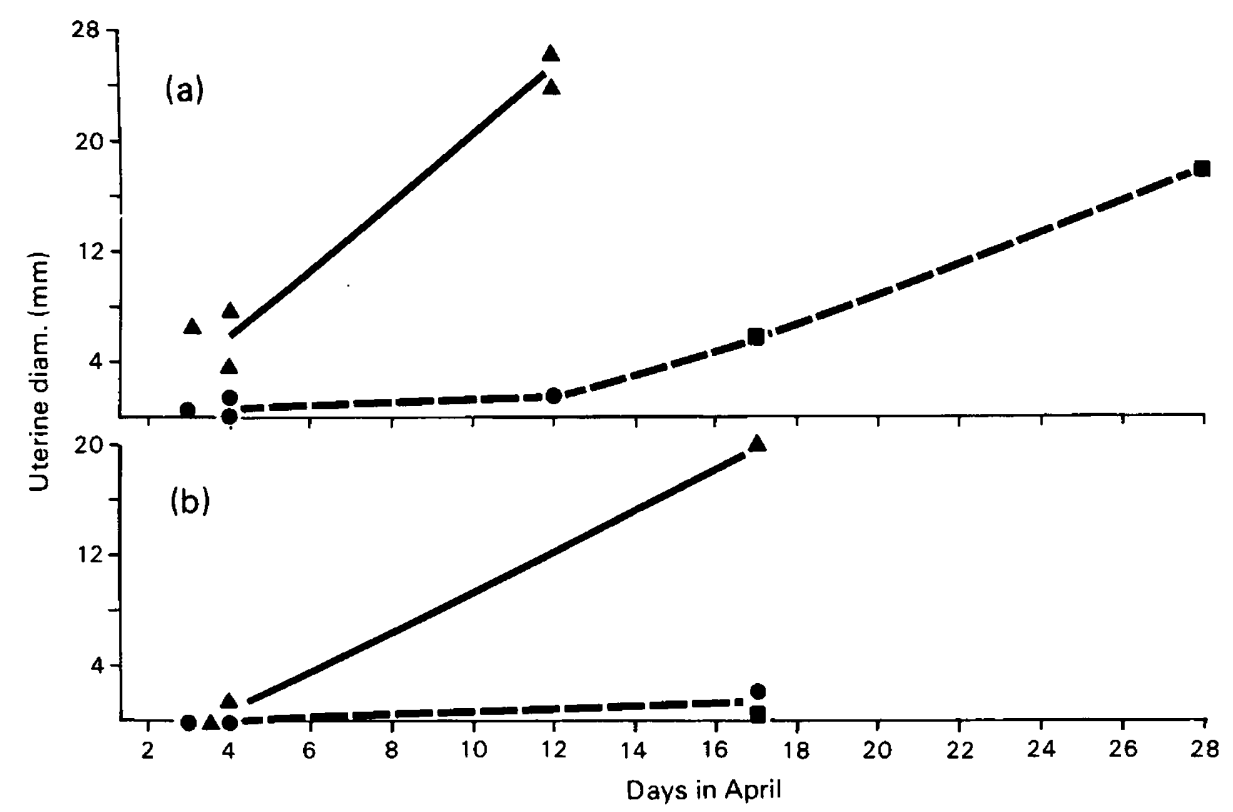

Text-fig. 1. Increases in uterine diameters at implantation sites of pregnant adult (a) and pubertal (b) mink mated on 4-5 March and subsequently receiving on 9-11 March injections of 2.5 mg $\mathrm{MPA} / \mathrm{kg}(\boldsymbol{\Delta})$, control vehicle $(\boldsymbol{)})$ or no injections $(\boldsymbol{\square})$. Each point represents one animal.

The results for pregnancy durations and litter sizes are summarized in Table 1 . The duration of pregnancy was clearly affected by the age of the animals and by treatment with MPA. All 4 mink whelping litters containing 8 or more kits had received MPA.

On 3-4 April mean \pm s.e.m. serum progesterone concentration in 5 MPA-treated females $(27.6 \pm 6.0 \mathrm{ng} / \mathrm{ml})$ was not significantly different from that in 5 control females $(19.4 \pm 7.0$ $\mathrm{ng} / \mathrm{ml})$. Similarly, the difference between adults $(29 \cdot 1 \pm 5.8 \mathrm{ng} / \mathrm{ml}, \mathrm{N}=6)$ and pubertal females 


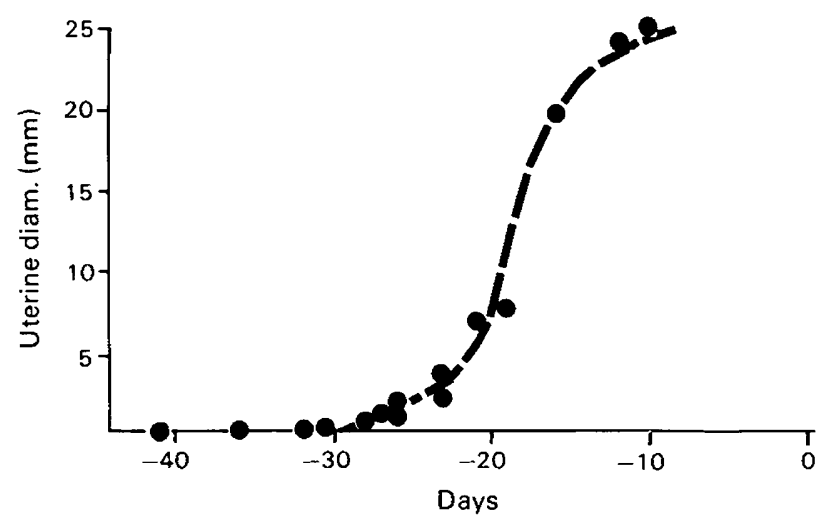

Text-fig. 2. Increases in uterine diameters at implantation sites of pregnant mink (adult and pubertal, treated and control) in relation to the time of parturition (Day 0). Each point represents one animal.

Table 1. Lengths of pregnancy and sizes of litters in adult and pubertal mink treated with MPA during early embryonic diapause (see text)

\begin{tabular}{|c|c|c|c|c|}
\hline & \multicolumn{2}{|c|}{ Adult mink } & \multicolumn{2}{|c|}{ Pubertal mink } \\
\hline & Controls & MPA-treated & Controls & MPA-treated \\
\hline No. of mink mated on $4 \mathrm{March}$ & 5 & 5 & 5 & 5 \\
\hline No. of mink whelping & 5 & 5 & 4 & 5 \\
\hline \multicolumn{5}{|l|}{ Length of pregnancy (days) } \\
\hline $\begin{array}{l}\text { Mean } \pm \text { s.e.m. } \\
\text { Range }\end{array}$ & $\begin{array}{l}60 \cdot 4 \pm 2 \cdot 0^{b} \\
56-67\end{array}$ & $\begin{array}{l}51 \cdot 0 \pm 0 \cdot 8^{c} \\
50-54\end{array}$ & $\begin{array}{l}72 \cdot 0 \pm 0 \cdot 7^{a} \\
70-73\end{array}$ & $\begin{array}{c}59 \cdot 8 \pm 1 \cdot 6^{b} \\
56-64\end{array}$ \\
\hline \multicolumn{5}{|l|}{ Litter size (kits/litter) } \\
\hline $\begin{array}{l}\text { Mean } \pm \text { s.e.m. } \\
\text { Range }\end{array}$ & $\begin{array}{c}4.40 \pm 0.5 \\
3-6\end{array}$ & $\begin{array}{c}5 \cdot 20 \pm 1 \cdot 3 \\
1-8\end{array}$ & $\begin{array}{c}4 \cdot 25 \pm 0 \cdot 9 \\
2-7\end{array}$ & $\begin{array}{c}5 \cdot 40 \pm 1 \cdot 6 \\
1-9\end{array}$ \\
\hline
\end{tabular}

Values with different superscripts are significantly different $(P<0.01$ by LSD).

$(15.0 \pm 5.7 \mathrm{ng} / \mathrm{ml}, \mathrm{N}=4)$ was not significant. The MPA values at this time were $3.4 \pm 0.3$ $\mathrm{ng} / \mathrm{ml}$ in the treated animals and non-detectable $(<0.8 \mathrm{ng} / \mathrm{ml})$ in the controls. On 28 April serum progesterone values were 9.0 and $17.1 \mathrm{ng} / \mathrm{ml}$ in 2 pubertal controls, 15 and 17 days pre partum, respectively, and 2.3 and $2.4 \mathrm{ng} / \mathrm{ml}$ in 2 MPA-treated adults, 5 and 4 days post partum, respectively. Serum MPA concentrations were undetectable in all 4 females on 28 April.

\section{Discussion}

The results of the present study appear to provide the first unequivocal evidence that administration of an exogenous progestagen can advance the normal times of blastocyst activation, implantation and parturition in a species exhibiting an obligate delay in implantation. Such results suggest that during normal pregnancy embryonic diapause is terminated by rising progesterone levels.

The observation that implantations were initially visible 28 days before parturition is in agreement with the conclusion of Enders (1952) that implantation in the mink occurs 28-30 days pre partum. The mean date of parturition in pubertal mink was 12 days later than that of adults (Table 1) but the extent of this difference may be atypical. Previously reported corresponding differences were only 2 (Enders, 1952) and 7 (Pilbeam et al., 1979) days. The reason for later implantation in pubertal mink is unclear. Normal implantation follows the initial 
increase in progesterone by about 10 days (Møller, 1973; Murphy \& Moger, 1977; Pilbeam et al., 1979). However, possible differences between pubertal and adult mink in the time of the initial increase in progesterone have not been reported. The increased durations of diapause and pregnancy in pubertal mink in comparison to those in adults were also observed in the MPAtreated animals.

Because of the limited nature of the present study, few, if any, conclusions can be made regarding the mechanism(s) whereby the administration of MPA during embryonic diapause, at 5 and 7 days after mating, induced precocious implantation. During normal pregnancy the initiation of the protracted elevation in serum progesterone levels may act to initiate the establishment of the uterine milieu necessary for blastocyst activation, migration and expansion. If that is the case, MPA, as a progestagen administered during diapause, may have initiated these uterine changes early, thus advancing blastocyst development. Observations on implantation times and times of parturition suggested that on 3-4 April implantation had already occurred in 8 of 10 MPA-treated mink whereas implantation had not then occurred in 8 of 9 pregnant control mink although serum progesterone levels were similar at that time. It is possible that MPA treatment could have advanced the initiation of progesterone secretion before this date, but earlier collection of blood samples would be necessary to check this. Additional studies will also be required to determine whether the termination of diapause by the administration of MPA to mink can serve as a useful experimental method to study the factors controlling implantation in this species.

We thank the Mink Farmers Research Foundation for their continuing support of these investigations; Mr W. Gardner and Mr P. Burke for care of animals; and Dr K. Kirton, Upjohn Company, for the Depo-Provera, MPA standard and the antisera to progesterone and MPA.

\section{References}

Allais, C. \& Martinet, L. (1978) Relation between daylight ratio, plasma progesterone levels and timing of nidation in mink. J. Reprod. Fert. 54, 133136.

Asdell, S.A. (1964) Patterns of Mammalian Reproduction, pp. 457-460. Cornell University Press, Ithaca, New York.

Aulerich, R.J., Holcomb, L., Ringer, R.K. \& Schaible, P.J. (1963) Influence of photoperiod on reproduction in mink. Q. Bull. Mich. St. Univ. agric. Exp. Stn 46, 132-138.

Cochrane, R.L. \& Shackelford, R.M. (1962) Effects of exogenous oestrogen alone and in combination with progesterone on pregnancy in the intact mink. $J$. Endocr. 25, 101-106.

Cornette, J.C., Kirton, K.T. \& Duncan, G. (1971) Measurement of medroxyprogesterone acetate (Provera) by radioimmunoassay. J. clin. Endocr. Metab. 33, 459-466.

Devilla, G., Jr, Roberts, K., Wiest, W.G., Mikhail, G. \& Flickinger, G. (1972) A specific radioimmunoassay of plasma progesterone. J. clin. Endocr. Metab. 35, $458-460$.

Enders, R.K. (1952) Reproduction in the mink. Proc. Am. Phil. Soc. 96, 691-755.

Franklin, B.C. (1958) Studies on the effects of progesterone on the physiology of reproduction in the mink. Ohio J. Sci. 58, 163-170.
Hammond, J., Jr (1951) Failure of progesterone treatment to affect delayed implantation in the mink. $J$. Endocr. 7, 330-334.

Hansel, W., Concannon, P.W. \& McEntee, K. (1977) Plasma hormone profiles and pathological observations in medroxyprogesterone acetate-treated Beagle bitches. In Pharmacology of Steroid Contraceptive Drugs, pp. 145-161. Eds S. Garattini \& H. W. Berendes. Raven Press, New York.

Hansson, A. (1947) The physiology of reproduction in mink (Mustela vison, Schreb) with special reference to delayed implantation. Acta zool. Stockh. 28, 1136.

Henderson, C.R. (1959) Design and Analysis of Animal Husbandry Experiments, pp. 2-56. ASAS Monograph, Techniques and Procedures in Animal Production Research. Am. Soc. Anim. Prod., Beltsville.

Holcomb, L.C. (1967) Effects of progesterone treatments on delayed implantation in mink. Ohio J. Sci. 67, 2431.

Holcomb, L.C., Schaible, P.J. \& Ringer, R.K. (1962) The effects of varied lighting regimes on reproduction in mink. Q. Bull. Mich. St. Univ. agric. Exp. Stn 44, $666-678$.

Kirton, K. \& Cornette, J.C. (1974) Return of ovulatory cyclicity following an intramuscular injection of medroxyprogesterone acetate (Provera). Contraception 10, 39-45. 
Moller, O.M. (1973) The progesterone concentration in the peripheral plasma of the mink during pregnancy. J. Endocr. 56, 121-132.

Murphy, B.D. \& Moger, W.H. (1977) Progestins of mink gestation: the effects of hypophysectomy. Endocr. Res. Commun. 4, 45-60.

Pilbeam, T.E., Concannon, P.W. \& Travis, H.F. (1979) The annual reproductive cycle of mink. J. Anim. Sci. 48, 578-584.
Steel, R.D.G. \& Torrie, J.M. (1960) Principles and Procedures of Statistics. McGraw-Hill Book Co., New York.

Travis, H.F. Schaible, P.J. (1959) Fundamentals of mink ranching. Circ. Bull. Mich. St. Univ. agric. Exp. Sin No. 229.

Venge, O. (1973-1974) Reproduction in the mink. U.K. and Ireland Fur Farming Gazette 23, 24-41; 24, $18-24 ; 24,13-21 ; 24 ; 20-26$.

Received 18 December 1978 